OPEN ACCESS

Edited by: Giuseppe Ferrara, University of Bari, Italy

Reviewed by:

Maurizio Boselli,

University of Verona, Italy

Fernando Martinez De Toda, Universidad de La Rioja, Spain

${ }^{*}$ Correspondence: Stefano Pon stefano.poni@unicatt.it

Specialty section:

This article was submitted to Crop Science and Horticulture, a section of the journa Frontiers in Plant Science

Received: 27 February 2016 Accepted: 29 April 2016 Published: 13 May 2016

Citation: GattiM, PirezFJ, Chiari G, TombesiS, Palliotti A, Merli MC and PoniS (2016)

Phenology, Canopy Aging and Seasonal Carbon Balance as Related to Delayed Winter Pruning of Vitis vinifera L. Cv. Sangiovese Grapevines. Front. Plant Sci. 7:659. doi: 10.3389/fp/s.2016.00659

\section{Phenology, Canopy Aging and Seasonal Carbon Balance as Related to Delayed Winter Pruning of Vitis vinifera L. Cv. Sangiovese Grapevines}

\author{
Matteo Gatti ${ }^{1}$, Facundo J. Pirez'1, Giorgio Chiari', Sergio Tombesi², Alberto Palliotti ${ }^{2}$ \\ Maria C. Merli1 and Stefano Poni ${ }^{1 *}$ \\ 1 Dipartimento di Scienze delle Produzioni Vegetali Sostenibili, Università Cattolica del Sacro Cuore, Piacenza, Italy, \\ 2 Dipartimento di Scienze Agrarie, Alimentari e Ambientali, Università di Perugia, Perugia, Italy
}

Manipulating or shifting annual grapevine growing cycle to offset limitations imposed by global warming is a must today, and delayed winter pruning is a tool to achieve it. However, no information is available about its physiological background, especially in relation to modifications in canopy phenology, demography and seasonal carbon budget. Mechanistic hypothesis underlying this work was that very late winter pruning (LWP) can achieve significant postponement of phenological stages so that ripening might occur in a cooler period and, concurrently, ripening potential can be improved due to higher efficiency and prolonged longevity of the canopy. Variability in the dynamics of the annual cycle was created in mature potted cv. Sangiovese grapevines subjected to either standard winter pruning (SWP) or late and very late winter pruning (LWP, VLWP) performed when apical shoots on the unpruned canes were at the stage of 2 and 7 unfolded leaves. Vegetative growth, phenology and canopy net $\mathrm{CO}_{2}$ exchange (NCER) were followed throughout the season. Despite LWP and VLWP induced a budburst delay of 17 and 31 days vs. SWP, the delay was fully offset at harvest for LWP and was reduced to 6 days in VLWP. LWP showed notably higher canopy efficiency as shorter time needed to reach maximum NCER/leaf area (22 days vs. 34 in SWP), highest maximum NCER/leaf area (+37\% as compared to SWP) and higher NCER/leaf area rates from veraison to end of season. As a result, seasonal cumulated carbon in LWP was 17\% higher than SWP. A negative functional relationship was also established between amount of leaf area removed at winter pruning and yield per vine and berry number per cluster. Although retarded winter pruning was not able to postpone lateseason phenological stages under the warm conditions of this study, it showed a remarkable potential to limit yield while improving grape quality, thereby fostering the hypothesis that it could be used to replace time-consuming and costly cluster thinning. This preliminary study indicates that proper winter pruning date should be timed so as not to exceed the stage of two unfolded leaves.

Keywords: Vitis vinifera L., gas exchange, source-sink balance, leaf age, photosynthesis, bud development 


\section{INTRODUCTION}

The relationship between leaf age and function in grapevine has been extensively studied in the past (Kriedemann, 1968; Poni et al., 1994; Patakas et al., 1997). A common feature of these studies, which were carried out under varying growing conditions and for different cultivars, is a rapid increase in leaf net photosynthesis $\left(\mathrm{P}_{\mathrm{n}}\right)$ from unfolding to 35-40 days of age that attends a rapid surge in chlorophyll and nitrogen leaf concentration. Once the peak is reached, $P_{n}$ rates thereafter usually start to decline at a rate depending upon environmental conditions, leaf exposure and source-to-sink balance (Chaumont et al., 1994). Working on Sangiovese vines grown without irrigation in the warm Po Valley, Poni et al. (1994) found that at 4 months of age leaf $\mathrm{P}_{\mathrm{n}}$ rates were halved compared to maximum rates reached at about 45 days; conversely, Schultz et al. (1996) found that maximum $\mathrm{P}_{\mathrm{n}}$ rates in Riesling vines grown in the cooler Rhine Valley stayed almost constant for approximately 3 months after reaching a peak at $\sim 30$ days of age.

Benefits derived from clarification of the above relationships are apparent since knowing how the $\mathrm{P}_{\mathrm{n}}$ vs. leaf age relationships works makes it easier to decide the right time and severity of summer pruning. Shoot trimming is indeed the benefit having the most profound effects on seasonal canopy demography and function. In fact, when shoots are trimmed, the canopy abruptly "ages" since the youngest leaves are removed but lateral regrowth triggered by shoot cuts rejuvenates the canopy and, eventually, the newly formed lateral leaves can become an important source for ripening (Poni and Giachino, 2000).

From a methodological standpoint, seasonal canopy demography and function are quite difficult processes to be studied since they depend upon changes in several factors inherent to the "population" of leaves composing the canopy, including age, light exposure, health status, shedding, and so forth. Inferring or extrapolating such complex interactions from single leaf-based assessment can lead to very rough approximations (Tarara and Peña, 2015). Good tools to achieving more reliable data are either modeling (Wermelinger et al., 1991; Cola et al., 2014) or the use of whole canopy gas-exchange systems (Garcia et al., 1990; Poni et al., 2014) since they can not only integrate multiple factors intervening at the canopy level in one reading but can be set up and maintained in place throughout the season, thereby delivering the needed continuous, long-term monitoring and evaluation of the entire process.

Canopy demography and function can also be changed according to the type and timing of winter pruning. For instance, the high vine-node number retained by hedge or minimal pruning is known to alter canopy filling and demography (Sommer et al., 1995). In a trial carried out on Chardonnay (Poni et al., 2000), minimally pruned vines exhibited a 4-6-fold higher $\mathrm{CO}_{2}$ fixation than hand pruned (HP) vines from about 3 weeks after bud burst to bloom. Canopy NCER started to recover in HP vines concurrently with the transition to a faster shoot growth phase; although by canopy completion NCER was still 13\% higher in MP.
Resorting to unusually late winter pruning (LWP) can be justified on the basis of a trend toward earlier than usual grape ripening marked by excessive and/or overly fast berry total soluble solids (TSS) accumulation and detrimentally high alcohol content in the resulting wine which has been reported in several countries (reviewed in Palliotti et al., 2014); alcohol concentration in Australian red wines has increased approximately $1 \% \mathrm{v} / \mathrm{v}$ per decade since the 1980s, for example (Varela et al., 2015). In many instances, and regardless of cultivar, these phenomena have also been coupled to unacceptably low total acidity (TA), high $\mathrm{pH}$ and atypical grape flavors shifting toward overripe and jammy attributes (Keller, 2010). This scenario has been the fillip for very active crop-management research to reduce ethanol concentration in wines (Varela et al., 2015). One promising practice among those proposed is post-veraison leaf removal in the upper two-thirds of a vertical canopy, i.e., apical to the cluster zone. Once again, the technique originates from the wellknown physiological background of the leaf age-leaf function relationship in grapevine: if ripening delay is sought, the rationale is that the most functional leaves have to be removed using a strategy that is the opposite of conventional basal-leaf removal. Poni et al. (2013) showed that TSS content in cv. Sangiovese grape must and wine alcohol concentration was significantly reduced (the latter by $0.6 \% \mathrm{v} / \mathrm{v}$ ) without any significant effect on other compositional parameters, including phenolic compounds. On the same variety, Palliotti et al. (2013) recommend mechanical leaf removal in a $50-\mathrm{cm}$ window at $15-16^{\circ}$ Brix to remove $30-35 \%$ of the leaf area. This practice can be done faster than conventional cluster-zone leaf removal and has the extra advantage, in a warm climate, that cluster zone exposure is minimally affected.

Delayed vine pruning in late winter or early spring has been studied since the second half of the last century (Antcliff et al., 1957), its primary aim being to postpone bud burst by few days and, hence, to increase the chances of escaping damaging spring frost in cool-climate growing areas (Howell and Wolpert, 1978). A more delayed spur-pruning (i.e., performed at the swollen bud phenological stage or later) is expected to modify vegetative growth and shift flowering, fruit-set and all subsequent phenological stages and impact fruit chemical composition at harvest. Friend and Trought (2007) have shown that very late pruning performed on Merlot grown in New Zealand when apical shoots on canes were about $5 \mathrm{~cm}$ long (i.e., October vs. the usual pruning time of July) caused lower sugar and higher organic acids content in grapes. Yet, to the best of our knowledge, no physiological assessment of how canopy demography, phenology and function are modified upon very late winter pruning (VLWP; i.e., when vegetative growth has already commenced) is currently available in literature. In lack of this basic information, calibration of the technique in regard to timing and modalities looks rather troublesome. Thus, the purposes of the present study were to: (a) determine if and how phenology and shoot growth and age are affected by LWP as compared to the standard practice; (b) assess seasonal wholecanopy net $\mathrm{CO}_{2}$ exchange rate in each treatment; and (c) provide estimates of seasonal carbon budget and establish preliminary correlations with yield components and final grape composition. Mechanistic hypothesis underlying this work was that VLWP 
can achieve significant postponement of phenological stages so that ripening might occur in a cooler period and, concurrently, ripening potential can be improved due to higher efficiency and prolonged longevity of the canopy.

\section{MATERIALS AND METHODS}

\section{Plant Material and Treatment Layout}

The trial was conducted in 2015 at Piacenza $\left(45^{\circ} 02^{\prime} \mathrm{N}, 9^{\circ} 43^{\prime} \mathrm{E}\right)$, Italy, on 5-year-old spur-pruned cv. Sangiovese vines (Vitis vinifera L) grafted on SO4 and grown outdoors in $40 \mathrm{~L}$ pots. Twelve vines were arranged along a single, vertically shootpositioned, $35^{\circ}$ NE-SW oriented row and hedgerow-trained. Each vine had a $\sim 1 \mathrm{~m}$ long cordon bearing six 2 -count node spurs that was raised $90 \mathrm{~cm}$ from the ground with three pairs of surmounting catch wires for a canopy wall extending about $1.3 \mathrm{~m}$ above the main wire. The pots were filled with a mixture of sand, loam and clay $(65,20$, and $15 \%$ by volume, respectively) and kept well-watered throughout the whole trial. Pots were palegreen colored to limit radiation-induced overheating and each vine was fertilized twice (i.e., 1 week before and 2 weeks after respective bud-break dates) with $4 \mathrm{~g}$ of Greenplant $15(\mathrm{~N})+5$ $\left(\mathrm{P}_{2} \mathrm{O}_{5}\right)+25\left(\mathrm{~K}_{2} \mathrm{O}\right)+2(\mathrm{MgO})+$ micro (Green Has Italia, Cuneo, Italy).

In winter, the vines were arranged in four blocks each of three vines and each vine randomly assigned to (a) standard winter pruning (SWP) performed on 19 February when all buds were still dormant, (b) LWP performed when, on average, the two apical shoots on the unpruned canes were at the $\mathrm{BBCH}$ 12 (i.e., two leaves unfolded according to Lorentz et al., 1995), and (c) VLWP performed when, on average, the two apical shoots on the unpruned canes were at the BBCH-17 stage (i.e., seven leaves unfolded corresponding to $\mathrm{BBCH}-53$ ) (Figure 1). Dates of LWP and VLWP were 13 April (DOY 103) and 29 April (DOY119), respectively. Due to asynchrony in canopy development, shoots were trimmed on 1 July (DOY 182) in both SWP and LWP, whereas trimming was performed 2 weeks later
A

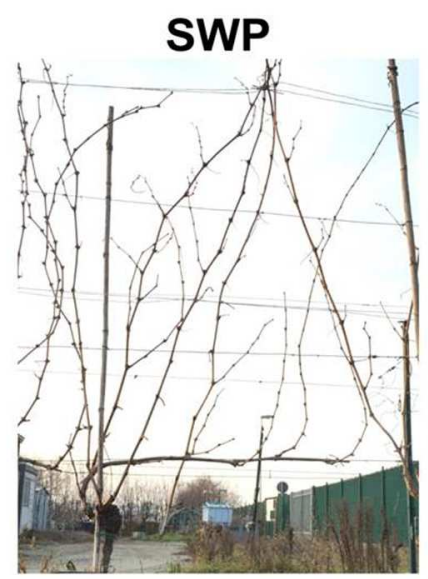

B

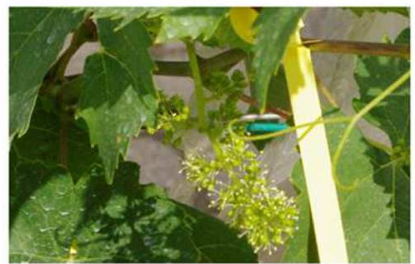

C

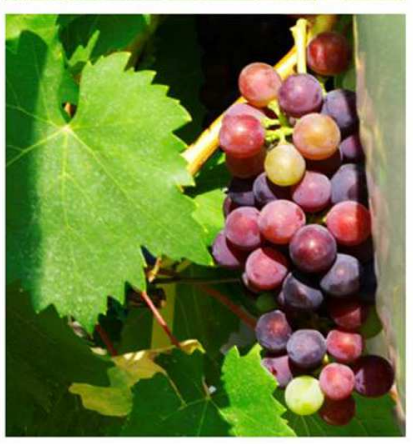

LWP
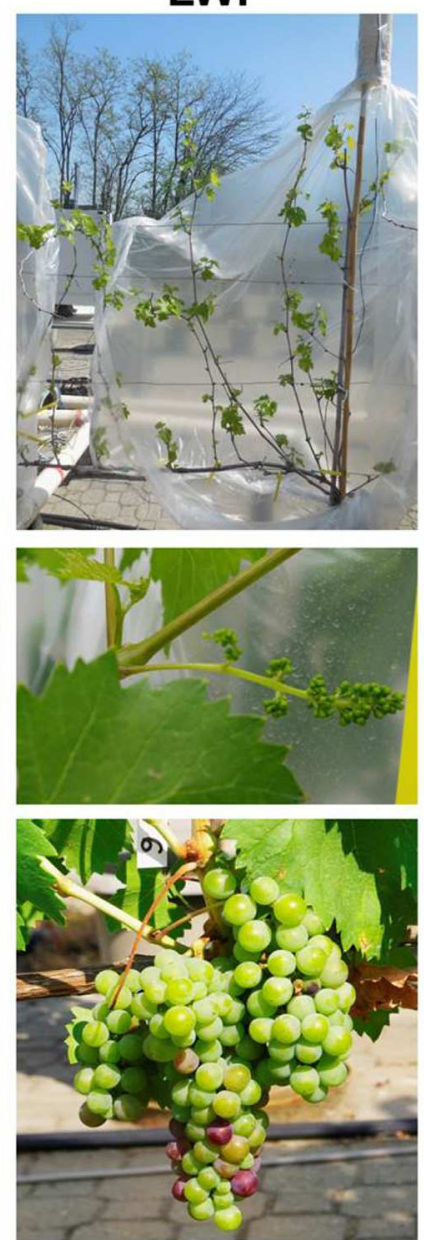

VLWP
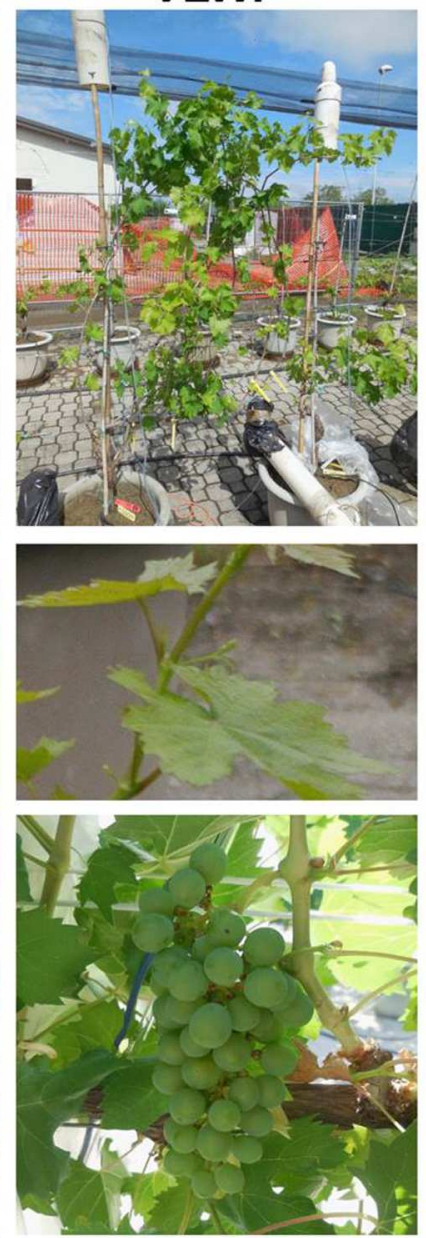

FIGURE 1 | Pictures showing vine appearance at the time winter pruning was performed (A), at BBCH-65 (B, SWP taken as reference) and at BBCH-81 (C, SWP taken as reference). 
A

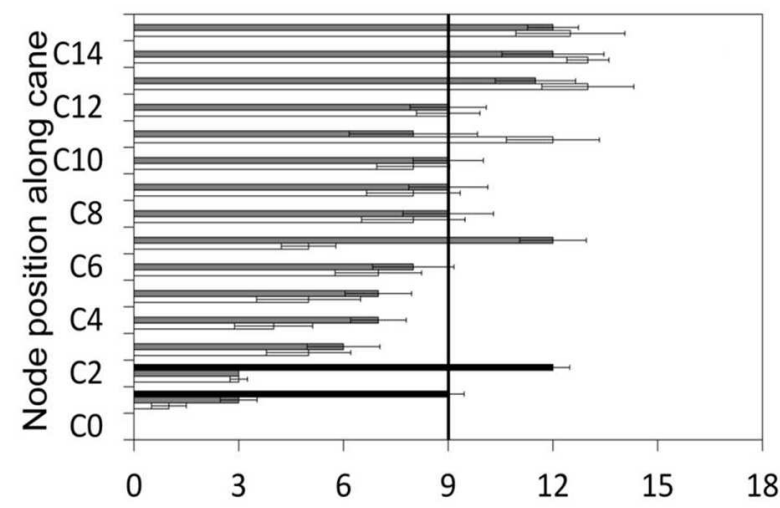

C



B

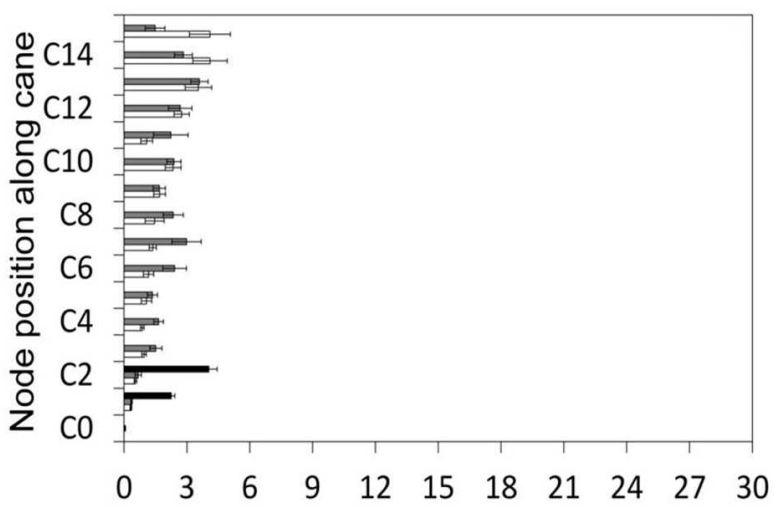

D

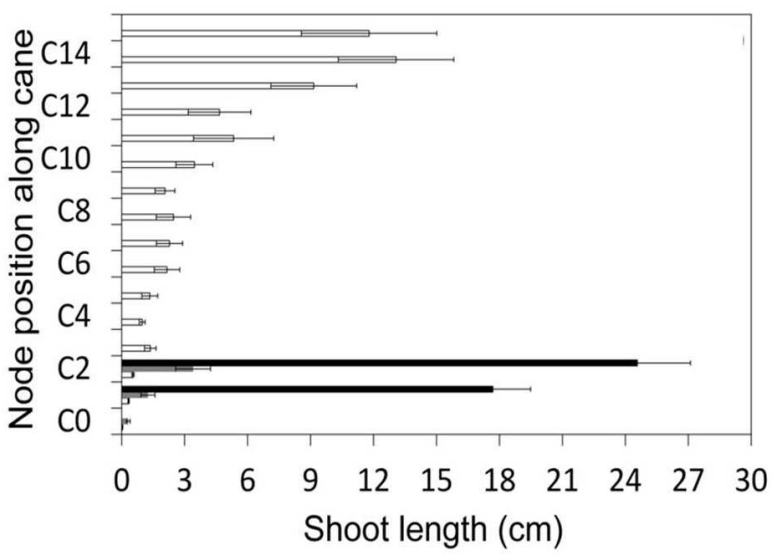

FIGURE 2 | Gradient of canopy growth along the cane recorded for the three pruning treatments before late winter pruning (LWP) (top panels) and very late winter pruning (VLWP) (bottom panels). Growth is given both as $\mathrm{BBCH}$ phase (A,C) and shoot length (B,D). $\mathrm{C}_{n}$ represents node position along the cane. Vertical bars on the left side of panels indicate bud-burst according to BBCH scale (Lorentz et al., 1995).

(DOY 197) on VLWP. Four of the six spurs retained per vine were enclosed in chambers for continuous gas-exchange monitoring; the remaining two (i.e., those inserted at distal cordon positions) were left un-chambered in order to assure free access for detailed growth and phenology readings.

\section{Vegetative Growth, Phenology, Yield Components and Grape Composition}

On 20 May the leaf area of 10 shoots randomly collected from additional Sangiovese vines was determined by measuring the surface of each lamina via a leaf area meter (LI-3000A, LI-COR Biosciences, Lincoln, NE, USA). Shoot length (y), ranging between 10 and $150 \mathrm{~cm}$, was correlated with the corresponding shoot leaf area $(\mathrm{x})$ and the resulting regression equation $y=0.67 \mathrm{x}^{2}+2.76 \mathrm{x}, R^{2}=0.90$ was then used for daily estimates of canopy leaf area. Values were adjusted expost according to final actual single leaf surface determined per treatment at the end of the trial.

The main leaves inserted on nodes $3,6,9,12,15,18$, and 21 of the distal shoot of both un-chambered spurs were collected on each vine at harvest and their surface measured with the leaf area meter. At the same time mean lateral leaf size was determined on a representative sample randomly collected from laterals. Immediately after leaf fall, total nodes per cane were counted as well as the number of nodes of each lateral shoot; final leaf area per vine was then estimated on the basis of node counts and leaf blade areas.

Chambers were temporarily dismantled for harvest at $\mathrm{BBCH}$ 89 on 26 August (SWP and LWP) and 4 September (VLWP). Each vine was individually picked and all clusters were counted and weighed, considering the six spurs as sub-replicates. The number of seeded and seedless berries was counted, rachis length measured and total berries per cluster were computed as the sum of seeded and seedless grapes, excluding shot berries. Cluster compactness was then calculated and expressed both as total berry fresh mass and total berries/rachis plus main wing length ratios (Tello and Ibanez, 2014).

A 50-berry sample was taken from each of the six subsamples per vine at harvest to ensure that the positions within the cluster (top, mid, bottom) and exposures (internal or external berries) were represented; these samples were then weighed and stored at $-20^{\circ} \mathrm{C}$ for subsequent analyses. All the 


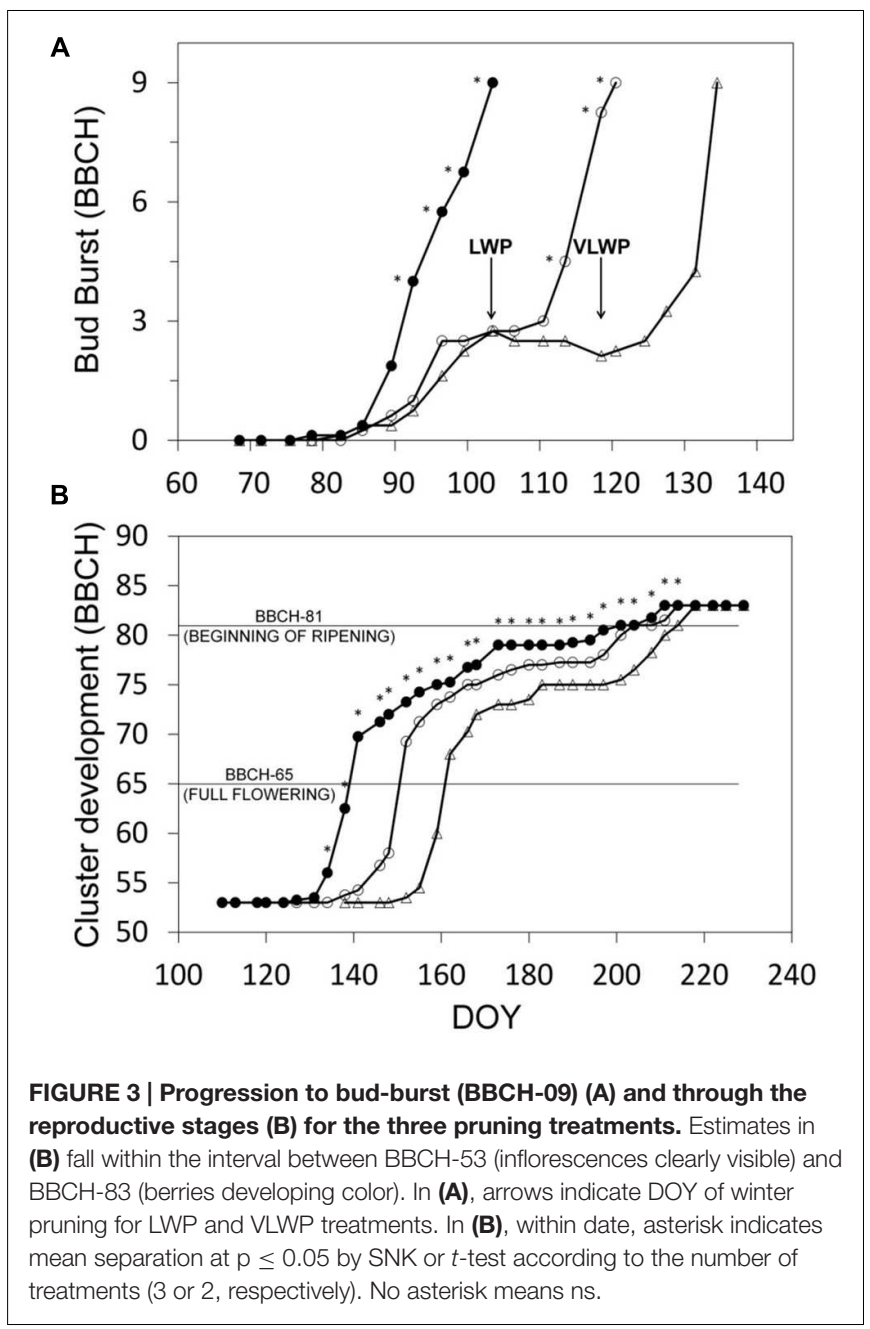

remaining crop was crushed, must TSSs concentration ( $\left.{ }^{\circ} \mathrm{Brix}\right)$ determined and titratable acidity (TA) measured by titration with $0.1 \mathrm{~N} \mathrm{NaOH}$ to a $\mathrm{pH} 8.2$ end point and expressed as $\mathrm{g} / \mathrm{L}$ of tartaric acid equivalents. Tartrate was assessed on must via the colorimetric method based on silver nitrate and ammonium vanadate reactions (Lipka and Tanner, 1974). Malate was determined with a kit (Megazyme Int., Bray, Ireland) that uses L-malic dehydrogenase to catalyze the reaction between malate and $\mathrm{NAD}^{+}$to oxaloacetate and $\mathrm{NADH}$. The reaction products were measured spectrophotometrically by the change in absorbance at $340 \mathrm{~nm}$ from the reduction of $\mathrm{NAD}^{+}$to $\mathrm{NADH}$. Potassium $\left(\mathrm{K}^{+}\right)$concentration was measured in the must using an ion-selective electrode (Model 96-61, Crison, Carpi, Italy).

Anthocyanins and phenolic substances were determined after Iland (1988) using the 50-berry sample left to thaw and then homogenized at high speed $(7602 \mathrm{~g}$ ) with an Ultra-Turrax (Rose Scientific Ltd, Edmonton, AB, Canada) homogenizer for $1 \mathrm{~min}$. Two grams of the homogenate were transferred to a pre-tarred centrifuge tube, enriched with $10 \mathrm{~mL}$ aqueous ethanol $(50 \%, \mathrm{pH}$ 5.0 ), capped and mixed periodically for $1 \mathrm{~h}$ before centrifugation at $959 \mathrm{~g}$ for $5 \mathrm{~min}$. A portion of the extract $(0.5 \mathrm{~mL})$ was added to
$10 \mathrm{~mL} 1 \mathrm{M} \mathrm{HCl}$, mixed and let stand for $3 \mathrm{~h}$; the absorbance values were then measured at 520 and $280 \mathrm{~nm}$ on a JascoV-530 UV spectrophotometer (Jasco Analytical Instruments, Easton, MD, USA). Anthocyanins and phenolic substances were expressed as $\mathrm{mg} / \mathrm{g}$ of FM and mg/berry.

\section{Whole-Canopy Gas Exchange}

Whole-canopy net $\mathrm{CO}_{2}$ exchange rate (NCER) measurements were taken using the multi-chamber system reported in Poni et al. (2014). In order to capture whole-season carbon balance changes in each treatment, the chambers were set up on each vine when all buds were still dormant (13 March, DOY 72) and continuously operated $24 \mathrm{~h}$ per day until 5 November (DOY 309) when leaf shedding had already started. Chambers were temporarily dismantled three times during the season for periods never exceeding a week in length to allow sprays, canopy management operations and manual harvest. The flow rate fed to the chambers was progressively adjusted according to the increasing leaf area enclosed in the chambers and varied from $2.8 \mathrm{~L} / \mathrm{s}$ set at the beginning of growth to $15.6 \mathrm{~L} / \mathrm{s}$ imposed when canopies reached their final size. Ambient (inlet) air temperature and the air temperature at each chamber's outlet were measured by shielded 1/0.2 mm diameter PFA -Teflon insulated type-T thermocouples (Omega Eng. INC, Stamford, Connecticut); direct and diffuse radiation were measured with a BF2 sunshine sensor (DeltaT Devices Ltd., Cambridge, UK) placed horizontally on top of a support stake next to the chambers enclosing the canopies. Canopy NCER ( $\mu \mathrm{mol} \mathrm{CO} 2 / \mathrm{s}$ ) was calculated from flow rates and $\mathrm{CO}_{2}$ differentials after Long and Hallgren (1985).

\section{Data Analysis}

One-way analysis of variance was carried out and, in case of significance of $F$-test, mean separation was performed by the Student-Newman-Keuls test at $P<0.05$ and 0.01 . BBCH readings were transformed into root squared values prior to analysis. Table-Curve 2D (Systat Software Inc., London, UK) was use to run polynomial regressions. Degree of variation around means is given as standard error (SE).

\section{RESULTS}

\section{Phenology and Demography}

The gradient of vegetative growth along the unpruned canes of LWP indicates that prior to pruning performed on DOY 103, the two apical shoots had reached the $\mathrm{BBCH}$ stage of two unfolded leaves, corresponding to a shoot length of about $4 \mathrm{~cm}$ (Figures 2A,B). The two basal LWP nodes to be retained with spur pruning were at the end of the bud swelling stage (BBCH-03). The same day acrotony was also exhibited by the two-node SWP spurs, the distal one having already reached the two unfolded leaf-stage and the proximal one still lagging at bud burst. As expected, the growth gradient recorded immediately before VLWP pruning on 29 April (DOY 119) was more pronounced with the two apical shoots at 6-7 unfolded leaves and at $12-14 \mathrm{~cm}$ in length, also corresponding to $\mathrm{BBCH}-53$ (Figures 2C,D). By analogy to LWP, the two basal nodes of 
TABLE 1 | Seasonal evolution (DOY), cumulated degree days (DD) and cumulated net carbon (C) per vine at main phenological stages according to the BBCH coding (Lorentz et al., 1995).

\begin{tabular}{|c|c|c|c|c|c|c|c|c|c|}
\hline \multirow[b]{2}{*}{ BBCH code } & \multicolumn{3}{|c|}{ SWP } & \multicolumn{3}{|c|}{ LWP } & \multicolumn{3}{|c|}{ VLWP } \\
\hline & DOYA & $\mathrm{DD}^{\mathrm{B}}\left({ }^{\circ} \mathrm{C}\right)$ & $c^{c}(g)$ & DOY & $\mathrm{DD}\left({ }^{\circ} \mathrm{C}\right)$ & $C(g)$ & DOY & $\mathrm{DD}\left({ }^{\circ} \mathrm{C}\right)$ & $C(g)$ \\
\hline 01 - Beginning of bud swelling & 87 & 7 & -5.6 & $92(5)$ & 29 & - & $93(6)$ & 32 & - \\
\hline O3 - End of bud swelling & 90 & 21 & -6.9 & $110(20)$ & 95 & -3.7 & $126(36)$ & 204 & -6.5 \\
\hline 09 - Bud burst & 103 & 59 & -11.6 & $120(17)$ & 152 & -10.4 & $134(31)$ & 295 & -12.5 \\
\hline 15 - 5 leaves unfolded & 116 & 134 & -10.7 & $132(16)$ & 269 & -12.8 & $143(27)$ & 369 & -16.9 \\
\hline 20 - 10 leaves unfolded & 133 & 282 & 23.4 & $146(13)$ & 395 & 32.1 & $155(22)$ & 504 & 0.44 \\
\hline $\begin{array}{l}61 \text { - Beginning of flowering } \\
\text { (10\% of flowerhoods fallen) }\end{array}$ & 137 & 323 & 42.0 & $149(12)$ & 423 & 53.8 & $160(23)$ & 588 & 19.6 \\
\hline $\begin{array}{l}65 \text { - Full flowering ( } 50 \% \text { of } \\
\text { flowerhoods fallen) }\end{array}$ & 139 & 347 & 53.2 & $151(12)$ & 446 & 68.7 & $161(22)$ & 602 & 22.6 \\
\hline 71 - Fruit set & 145 & 387 & 89.2 & $154(9)$ & 486 & 92.5 & $167(22)$ & 678 & 52.1 \\
\hline 73 - Berries groat-sized & 151 & 446 & 143.1 & $159(8)$ & 574 & 145.7 & $173(22)$ & 753 & 95.7 \\
\hline 75 - Berries pea-sized & 159 & 574 & 225.0 & $166(7)$ & 667 & 212.3 & $183(24)$ & 903 & 182.4 \\
\hline 79 - Majority of berries touching & 173 & 753 & 383.6 & $199(26)$ & 1216 & 601.9 & $209(36)$ & 1411 & 377.9 \\
\hline 81 - Beginning of ripening & 201 & 1257 & 669.6 & 204 (3) & 1320 & 677.2 & $214(13)$ & 1485 & 413.3 \\
\hline 83 - Berries developing color & 211 & 1446 & 782.2 & $214(3)$ & 1485 & 796.2 & $218(7)$ & 1558 & 448.1 \\
\hline $\begin{array}{l}89 \text { - Berries ripe for harvest (19 } \\
{ }^{\circ} \text { Brix) }\end{array}$ & 238 & 1843 & 977.3 & $235(-3)$ & 1809 & 1012.4 & $244(6)$ & 1842 & 628.0 \\
\hline
\end{tabular}

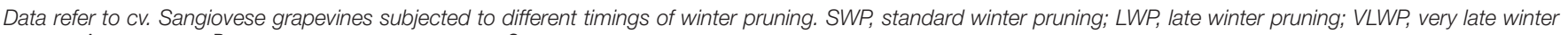

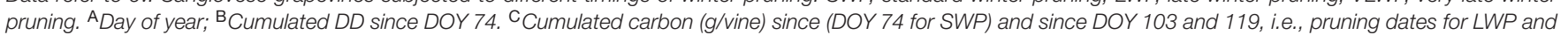
VLWP, respectively.

VLWP were still at bud swelling stages when pruning was performed on DOY 119.

Progression trends toward budburst showed that while bud opening in SWP was closely related to chronological time (from DOY $82, y=0.442 \mathrm{x}-36.806, R^{2}=0.98$ ), apical dominance in LWP kept the two basal buds at bud-swelling stages for 2 weeks prior to pruning and it took about 10 days to reactivate development after pruning (Figure 3A). In VLWP, the two basal nodes remained at bud swelling for approximately a month (DOY 89-119) and post-pruning resumption of bud development occurred in approximately 10 days. This dynamic led to a bud-burst delay of 17 and 31 days for LWP and VLWP vs. SWP, respectively (Table 1). The tendency in both late pruning treatments was to reduce this delay over the progressing season (Figure 3B; Table 1). At full flowering (BBCH 65) delay was 12 days for LWP and 22 days for VLWP, decreasing further at 3 and 13 days at the onset of ripening $(\mathrm{BBCH} 81)$. The grape sugar level set for ripening $\left(\sim 19{ }^{\circ}\right.$ Brix, equivalent to a potential alcohol of $\sim 11^{\circ}$ ) was reached by SWP on DOY 238, whereas the same level of ripeness was anticipated by $3 \mathrm{~d}$ in LWP and delayed by 6 days in VLWP (Table 1). Interestingly, maximum delay over the whole Lorentz et al. (1995) scale occurred at BBCH-79 (i.e., majority of berries touching) with 26 and 36 days for LWP and VLWP as compared to SWP.

While the number of days elapsing between bud burst and full bloom (BBCH-09 to BBCH-65) decreased with increasing winter pruning delay $(36,31$, and 27 days for SWP, LWP and VLWP, respectively), cumulated heat summation (DD) over the same interval was instead quite similar $\left(288,294\right.$, and $307^{\circ} \mathrm{C}$, respectively, Table 1). The same number of days (53) was needed by both late pruning levels to transit from full bloom to onset of ripening (BBCH-81) vs. 62 days required by SWP; cumulated DD was still notably close $(910,874,883$ DD for SWP, LWP and VLWP, respectively). The shift from onset of ripening to berries ripe for harvest (BBCH-89) took 37 days in SWP vs. 31 in LWP and 30 days in VLWP, whereas heat requirement for the same transition diminished along with pruning delay (i.e., 586, 489, and $457^{\circ} \mathrm{C}$ for SWP, LWP and VLWP, respectively). The full season growth cycle between bud burst and ripe berry harvest lasted from a maximum 135 days calculated for SWP to a minimum 113 days for VLWP, with LWP holding an intermediate position (118 days). Notably, while SWP required an $\Sigma \mathrm{DD}$ of $1784^{\circ} \mathrm{C}$ to complete the path, 1657 and $1647^{\circ} \mathrm{C}$ were needed by LWP and VLWP, respectively.

After shoot growth had commenced, shoot elongation was at any date different over treatments, and the relative differences stayed almost constant until shoot trimming halted growth (Figure 4A). Maximum shoot length pre-trimming was 191, 160, and $181 \mathrm{~cm}$ in SWP, LWP and VLWP, respectively (Figure 4A). At the respective full bloom (BBCH-65) dates, shoots had $\sim 12$ unfolded leaves, whereas shoot length was $60.4 \pm 6.2,61.1 \pm 8.6$, and $65.9 \pm 6.5 \mathrm{~cm}$ in SWP, LWP and VLWP, respectively. Expressing shoot development in terms of growth rates disclosed that upon commencement of shoot growth in VLWP, and despite the favorable thermal regime, pre-bloom growth rates were significantly lower ( $\sim 5 \mathrm{~cm} / 3-4$ days) than those recorded for the other two pruning dates, $\sim 10-12 \mathrm{~cm} / 3-4$ days (Figure 4B). Mean shoot age was consistently modified by treatments, resulting in $34.3 \pm 0.3,28.4 \pm 0.9$ and $29.1 \pm 0.4$ at pre-trimming 

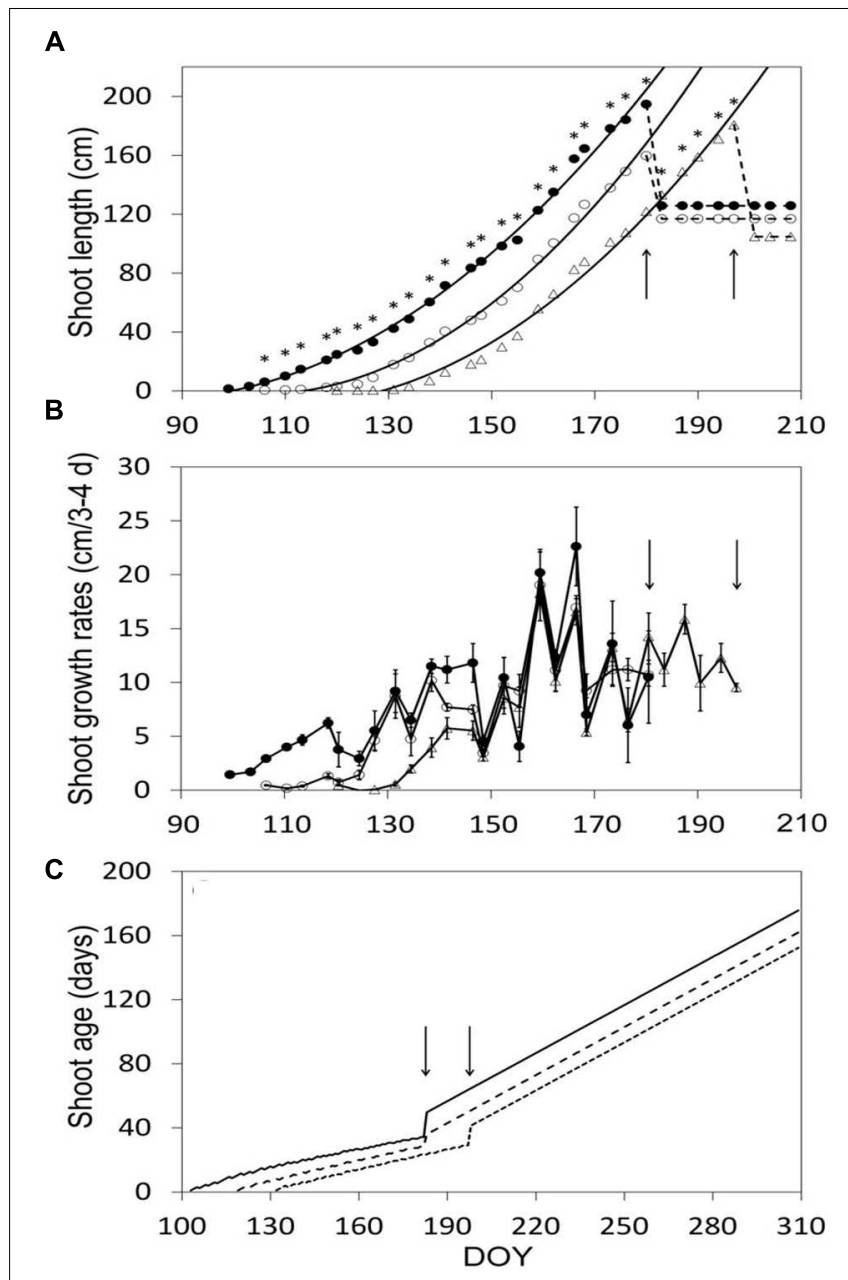

FIGURE 4 | Shoot elongation (cm, A), shoot growth rates (cm/3-4 days, B) and seasonal mean shoot age (days, C) as affected by winter pruning treatments. In (A) exponential equations fit to shoot elongation vs. DOY data were: $y=0.0229 x^{2}-3.8597 x+157.29\left(R^{2}=0.996\right)$, $y=0.0301 x^{2}-6.292 x+326.88\left(R^{2}=0.995\right)$ and $y=0.026 x^{2}-5.6918 x+302.21\left(R^{2}=0.992\right)$ in SWP, LWP and VLWP treatments, respectively. In (B) vertical bars represent standard errors (SE) around means. In all panels, arrows indicate dates of shoot trimming.

(Figure 4C). Trimming caused an expected and abrupt increase in shoot age, estimated at $50.7 \pm 0.6,37.0 \pm 2.8$, and $41.4 \pm 0.6$ in SWP, LWP and VLWP, respectively.

\section{Canopy Function}

Mean diurnal PAR and VPD recorded throughout the measuring period (DOY 72-309) notably fluctuated until about DOY 165; thereafter a long series of mostly clear days occurred until treatments were harvested (Figure 5A); air VPD peaked occasionally at $\sim 3 \mathrm{kPa}$. Average ambient $\mathrm{CO}_{2}$ concentration $\left[\mathrm{CO}_{2}\right]$ over the season was $398 \pm 12.4 \mu \mathrm{L} / \mathrm{L}$ (mean \pm standard deviation), whereas seasonal mean inlet air temperature (T) was $23.8 \pm 6.3^{\circ} \mathrm{C}$. Seasonal mean $\mathrm{T}$ measured at chambers' outlets was $25.1 \pm 5.9^{\circ} \mathrm{C}, 25.1 \pm 6.0^{\circ} \mathrm{C}$ and $24.8 \pm 5.7^{\circ} \mathrm{C}$ for SWP, LWP and VLWP, respectively, corresponding to an overheating

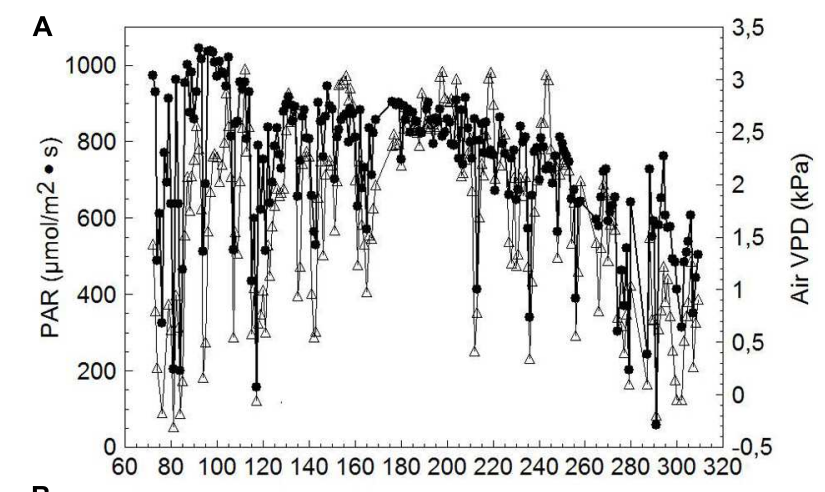

B

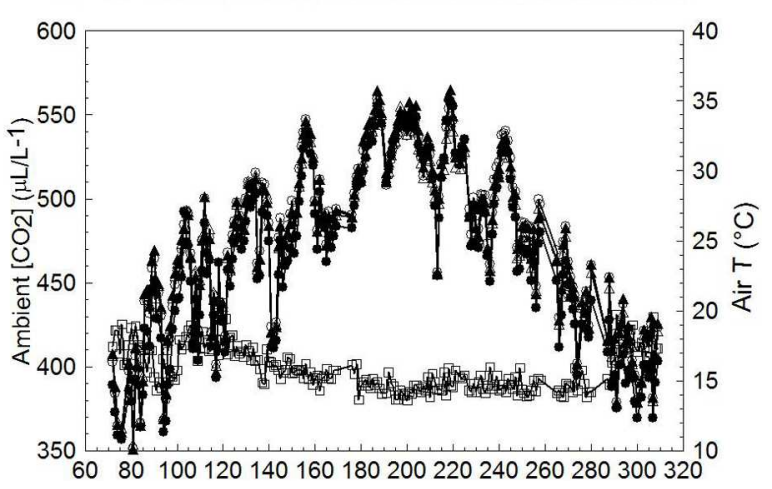

FIGURE 5 | Seasonal trends of incoming photosynthetically active radiation (PAR, $\bullet$ ), air vapor pressure deficit (VPD, $\Delta$ ) (A), inlet chamber air temperature $(T, \bullet)$, outlet chambers air temperature for SWP $(T, \circ)$, outlet chambers air temperature for LWP (T, $\Delta)$, outlet chambers air temperature for VLWP (T, $\Delta$ ) and ambient $\mathrm{CO}_{2}$ concentration ( $\square$ ) (B) measured at the trial site. Values are daily means averaged from dawn to dusk.

contained within $1.3^{\circ} \mathrm{C}$ for SWP and LWP and $1.0^{\circ} \mathrm{C}$ for VLWP (Figure 5B). An un-seasonably cool period registering inlet mean $\mathrm{T}$ of $\sim 17^{\circ} \mathrm{C}$ occurred on DOY $141-143$.

Comparison of seasonal canopy net $\mathrm{CO}_{2}$ exchange rate (NCER) for SWP and LWP shows that SWP started to show a positive NCER on DOY 119 when shoots were around BBCH-16 (Figures 6A,B, Table 1); the same threshold was reached on DOY 130 and $144(\sim \mathrm{BBCH}-15)$ in both LWP and VLWP. Maximum canopy NCER rates $(\sim 13-14 \mu \mathrm{mol} / \mathrm{s})$ were recorded in SWP on DOY 176 and 177, i.e., just prior to trimming and close to the $\mathrm{BBCH}-79$ (majority of berries touching). The peak in canopy NCER $(\sim 15.0-15.5 \mu \mathrm{mol} / \mathrm{s})$ was reached later (i.e., beginning of ripening) in LWP, whereas canopy NCER in VLWP was maximum both before and after shoot trimming with rates close to $9 \mu \mathrm{mol} / \mathrm{s}$. Shoot trimming performed on DOY 182 in SWP caused a temporary NCER drop of 25\%, calculated by comparing mean NCER over 3 days immediately before and after trimming (i.e., 12.2 vs. $9.2 \mu \mathrm{mol} / \mathrm{s})$. Reduction of canopy NCER in LWP due to trimming was milder $(-6 \%)$, whereas in VLWP trimming curtailed canopy NCER by $21 \%$. Over the 37-day ripening period (BBCH-81 to BBCH-89) daily mean canopy NCER was $8.8 \mu \mathrm{mol} / \mathrm{s}$ vs. $11.4 \mu \mathrm{mol} / \mathrm{s}$ in SWP and LWP, respectively; 



FIGURE 6 | Seasonal trends of daily mean canopy net $\mathrm{CO}_{2}$ exchange rate (NCER, $\mu \mathrm{mol} / \mathrm{s}$ ) measured in SWP vs. LWP (A) and SWP vs. VLWP (B) treatments. Vertical bars indicate standard error $(n=4)$. Dotted arrows indicate dates of LWP and solid arrows dates of shoot trimming.

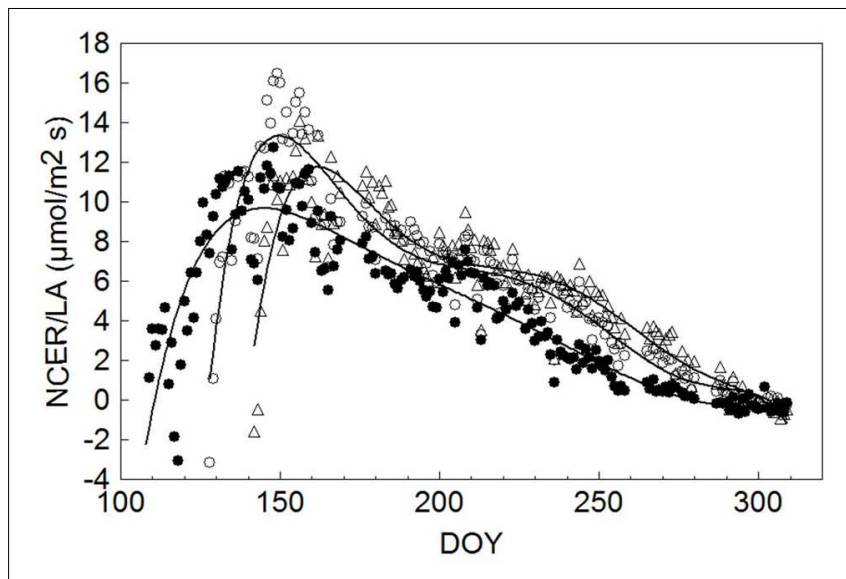

FIGURE 7 | Seasonal trends of daily mean canopy net $\mathrm{CO}_{2}$ exchange rate per unit leaf area (NCER/LA, $\mu \mathrm{mol} / \mathrm{m}^{2} \mathrm{~s}$ ) measured in SWP (•), LWP (o) and VLWP $(\Delta)$. Each data point is the mean of four vine replicates. For each treatment data were fitted by a six order high precision polynomial curve yielding $R^{2}=0.85$ in SWP, $R^{2}=0.89$ in LWP and $R^{2}=0.87$ in VLWP.

VLWP reached a mean NCER of $7.7 \mu \mathrm{mol} / \mathrm{s}, 15 \%$ less than SWP, over its 33-day ripening period (DOY 214 to DOY 247).



B

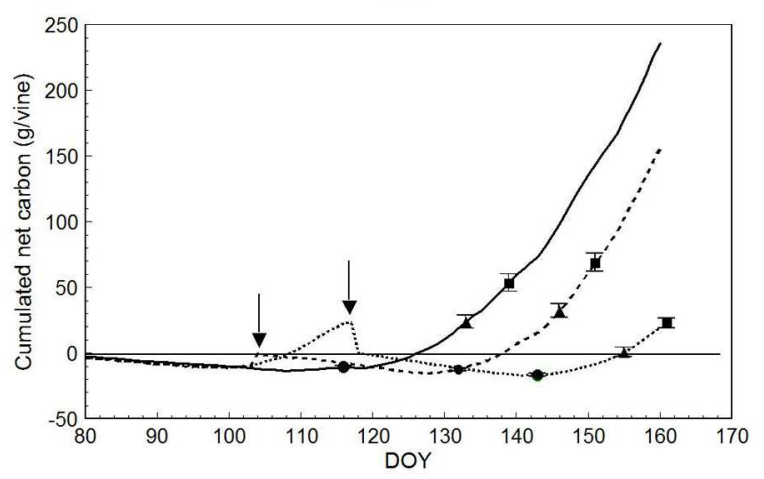

FIGURE 8 | Seasonal net carbon (C) accumulation (A) derived from the canopy photosynthesis monitoring for SWP (solid line), LWP (broken line) and VLWP (dotted line). On each line, • is for bud burst (BBCH-09), $\boldsymbol{\Delta}$ is for beginning of flowering ( $\mathrm{BBCH}-61), \boldsymbol{a}$ is for beginning of ripening $(\mathrm{BBCH}-81)$ and is for berries ripe for harvest $(\mathrm{BBCH}-89)$. For each phenological date, vertical bars indicate standard error $(n=4)$. In (B), seasonal net $\mathrm{C}$ accumulation is zoomed for early season, $\bullet$ is for five leaves unfolded (BBCH-15), $\mathbf{\Delta}$ is for 10 leaves unfolded $(\mathrm{BBCH}-20)$ and $\boldsymbol{\square}$ is for full flowering (BBCH-65). Arrows indicate dates of LWP. Vertical bars indicate SE around means.

To allow unbiased comparisons, seasonal NCER/LA trends for each treatment were interpolated by a sixth order high precision polynomial curve, indicating that maximum NCER/LA $\left(9.69 \mu \mathrm{mol} / \mathrm{m}^{2} \mathrm{~s}\right)$ for SWP occurred on DOY 145 , or 34 days after the system started to detect a net $\mathrm{CO}_{2}$ gain at DOY 111 (Figure 7). Thereafter a steady, yet gradual NCER/LA decline was recorded until net $\mathrm{CO}_{2}$ fixation was annulled on DOY 279. In both LWP and VLWP, maximum NCER/LA (13.3 and $11.8 \mu \mathrm{mol} / \mathrm{m}^{2} \mathrm{~s}$, respectively) was reached 22 days after the commencement of positive $\mathrm{CO}_{2}$ fixation and, while a similar gradual decline occurred thereafter, positive $\mathrm{CO}_{2}$ differentials were maintained in both pruning dates over DOY 300 .

Plotting cumulated seasonal net carbon (C) per vine (DOY 72 to DOY 309) resulted in different end-season values of $1243 \mathrm{~g} /$ vine in LWP vs. $1042(-16 \%)$ and $772(-38 \%) \mathrm{g} / \mathrm{vine}$ in SWP and VLWP, respectively (Figure 8A). Seasonal dynamics also differed (Figure 8B). While LWP pruning performed on DOY 103 slightly improved the net $\mathrm{C}$ balance, the opposite was seen in VLWP's: it had already reached a positive carbon balance the DOY 117 pruning date, i.e., $23.3 \mathrm{~g} /$ vine, but abruptly shifted to 
a negative balance. At $\mathrm{BBCH}-15$, all pruning treatments were still at a negative $\mathrm{C}$ balance, whereas at $\mathrm{BBCH}-20$ (10 leaves unfolded) the two earlier pruning treatments were positive (>20 g/vine) and VLWP was still around compensation ( $0.44 \mathrm{~g} / \mathrm{vine})$. These differences were amplified at the onset of flowering, and VLWP showed a much more limited $\mathrm{C}$ balance as compared to the other two pruning dates at every phenological stage thereafter. LWP progressively recovered the initial carbon gap when compared to SWP and accumulated carbon values overlapped by DOY 202, i.e., mid-way between veraison and full ripening (BBCH-89). Notably, carbon gain between BBCH 81 and 89 was 308, 358 and $233 \mathrm{~g} /$ vine for SWP, LWP and VLWP, respectively. Post-harvest C accumulated until the day of system dismantling, registering 61 , 199 and $126 \mathrm{~g} /$ vine, respectively.

\section{Vegetative Growth, Yield and Grape Composition}

While shoot number per vine did not differ among treatments, final canopy surface area was lower in VLWP as compared to the earlier pruning dates due to lower primary leaf area and smaller main leaf surface (Table 2). Devigoration in VLWP was also confirmed by lower total pruning weight and single cane mass. Total leaf area per vine removed at winter pruning was $3245 \pm 202 \mathrm{~cm}^{2}$ in LWP and $10945 \pm 954 \mathrm{~cm}^{2}$ in VLWP, corresponding to 9 and $39 \%$ of final total LA/vine, respectively.

Yield per vine was $28 \%$ lower in WLP than in SWP, although at the latest pruning date yield became negligible, i.e., just $145 \mathrm{~g} /$ vine (Table 3). LWP yield components contributing to the decrease were lower cluster weight and berry number per cluster; VLWP's main limiting factor was the drop in cluster/shoot to 0.29 and, secondarily, the fact that the few clusters it did develop were also miniaturized as compared to those resulting from the earlier pruning treatments. Although rachis length decreased proportionally with the delay in winter pruning, the concurrent decrease in berries/cluster offset this effect and, regardless of its expression, cluster compacteness showed a decreasing trend the more pruning was delayed, registering significance for VLWP (Table 3). Relative variations in vegetative growth and yield components caused the source availability vis-à-vis sink demand to increase the more pruning were delayed (last two columns in Table 3). On a more functional basis, a close negative and linear relationship ( $\left.\mathrm{y}=-0.1397 \mathrm{x}+1.721 .5, \mathrm{R}^{2}=0.87\right)$ was found between total LA/vine removed by pruning and yield per vine for data pooled over treatments (Figure 9). A less tight, albeit still significant, relationship was also found between removed LA and berry number per cluster at harvest $(y=-0.005 x+92.995$, $\left.\mathrm{R}^{2}=0.76\right)$.

For the two treatments concurrently picked at first harvest date on DOY 238, SWP fulfilled the expected ripening threshold set at $\sim 19^{\circ}$ Brix, whereas LWP registered higher concentrations of TSSs, by $1^{\circ}$, total anthocyanins and phenolics; $\mathrm{pH}$ and organic acid concentrations were unaffected (Table 4). LWP picked 6 d later than SWP (DOY 244), VLWP reached a must sugar concentration at $19.9^{\circ} \mathrm{Brix}$, similar to LWP's, but total anthocyanins were lower. Interestingly, despite the large source

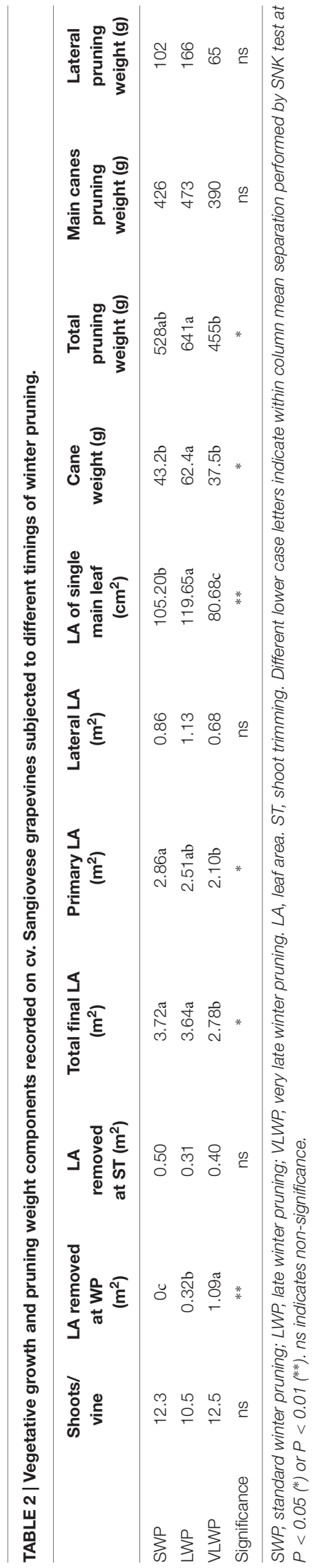




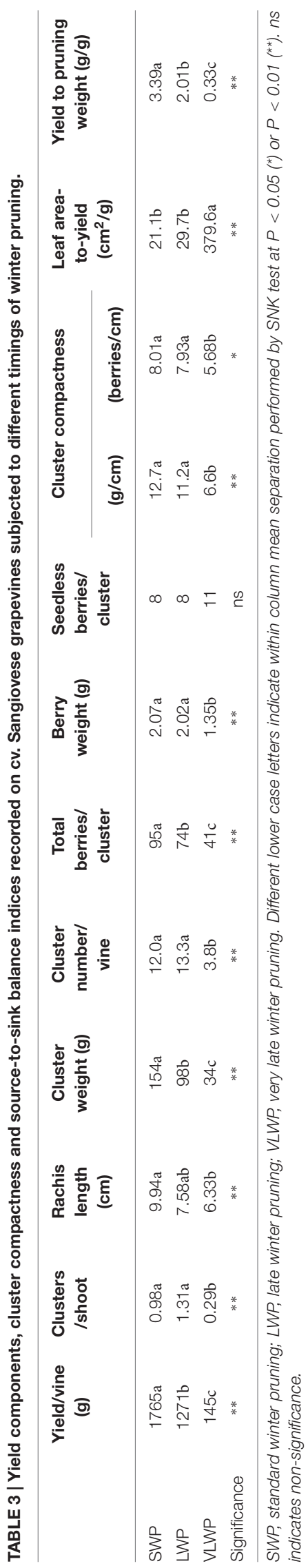

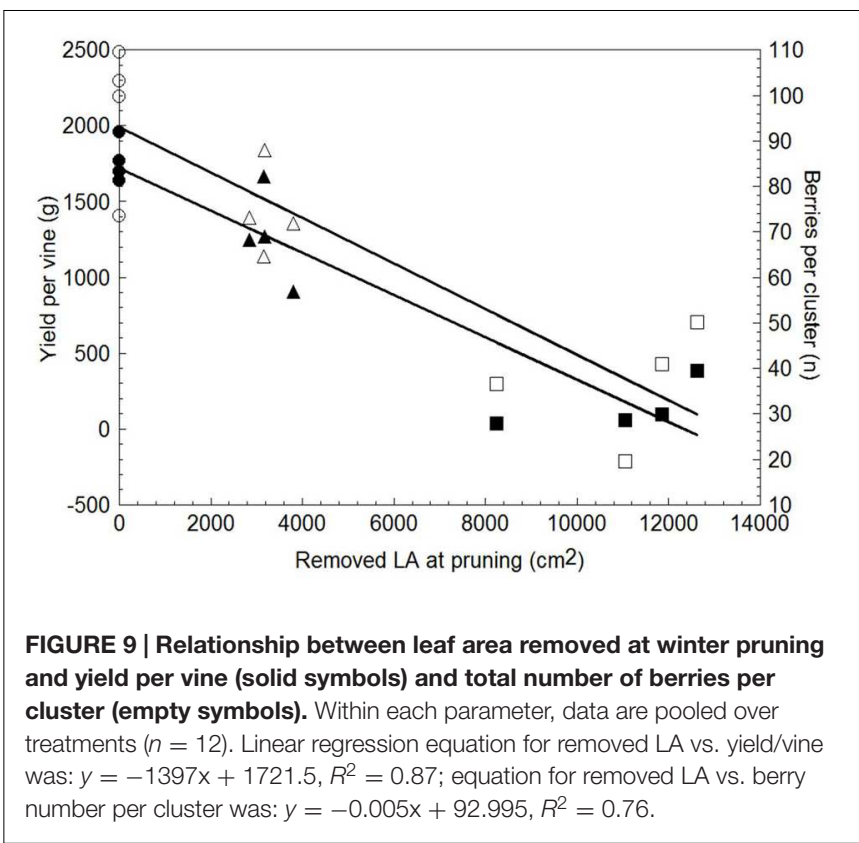

availability as compared to sink demand in VLWP, TA decline was delayed, especially in regard to lower degradation of malic acid.

\section{DISCUSSION}

The main point is understanding if and how retarded winter pruning might induce and maintain consistent ripening delay so as to lead grapes to maturity in a cooler period to offset detrimental effects of global warming (Varela et al., 2015). Since VLWP registered negligible crop, the issue focuses on a comparison of SWP and LWP. That pruning delay elicited an almost corresponding delay in bud burst in our study provides evidence that grapevine is a kind of ideal crop since the apical dominance exerted by the distal nodes on the subtending ones is very strong and stable (Figure 2). Indeed, it explains why the 16 days time/lapse between the two late pruning dates was very close to their 14 days time difference in bud burst (Table 1). Note, too, that the initial, consistent bud-break delay registered in LWP (+ 17 days vs. SWP) was fully offset at ripening.

Looking at chronological and thermal lapses between development stages shows that most of the recovery by LWP and VLWP took place from bud burst to full bloom and from the latter to the onset of ripening (Table 1). Since heat summation required to complete these shifts was very similar over treatments, it is apparent that the late-burst treatments benefited from higher post-bud burst temperatures, thereby allowing them to reach the required DD threshold in fewer days. These data confirm air temperature as the main driver and better predictor of bloom date than bud burst.

In a comprehensive study carried out over 7 years on 114 cultivars, McIntyre et al. (1982) evaluated the consistency of various climate indicators as time predictors of specific 
TABLE 4 | Parameters of grape composition recorded at harvest on cv. Sangiovese grapevines subjected to different timings of winter pruning.

\begin{tabular}{|c|c|c|c|c|c|c|c|c|c|}
\hline & $\begin{array}{l}\text { Total soluble } \\
\text { solids ( }{ }^{\circ} \text { Brix) }\end{array}$ & $\mathrm{pH}$ & $\begin{array}{c}\text { Titratable } \\
\text { acidity }(\mathrm{g} / \mathrm{L})\end{array}$ & $\begin{array}{l}\text { Tartaric } \\
\text { acid } \\
\text { (g/L) }\end{array}$ & $\begin{array}{c}\text { Malic acid } \\
\text { (g/L) }\end{array}$ & $\begin{array}{c}\text { Tartrate- } \\
\text { to-Malate } \\
\text { ratio }\end{array}$ & $\begin{array}{c}\mathbf{K}^{+} \\
(\mathbf{p p m})\end{array}$ & $\begin{array}{c}\text { Total } \\
\text { anthocyanins } \\
(\mathrm{mg} / \mathrm{g})\end{array}$ & $\begin{array}{c}\text { Total } \\
\text { phenolics } \\
\text { (mg/g) }\end{array}$ \\
\hline SWP & $19.2 b$ & 3.45 & $6.06 \mathrm{~b}$ & $8.20 \mathrm{~b}$ & $1.54 \mathrm{~b}$ & $5.54 a$ & 1800 & $0.43 b$ & $2.08 b$ \\
\hline LWP & $20.2 \mathrm{a}$ & 3.43 & $5.94 b$ & $8.04 b$ & $1.60 \mathrm{~b}$ & $5.13 a$ & 1759 & $0.65 a$ & $2.70 \mathrm{a}$ \\
\hline VLWP & $19.9 \mathrm{a}$ & 3.45 & $7.10 \mathrm{a}$ & $8.95 a$ & $2.23 \mathrm{a}$ & $4.16 \mathrm{~b}$ & 1870 & $0.48 b$ & $2.44 a$ \\
\hline Significance & $* *$ & ns & $* *$ & $* *$ & $* *$ & $*$ & ns & $* *$ & $* *$ \\
\hline
\end{tabular}

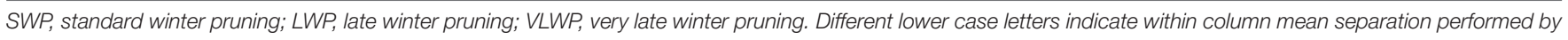
SNK test at $\left.P<0.05{ }^{*}\right)$ or $P<0.01\left(^{* *}\right)$. ns indicates non-significance.

phenological stages in the bud burst-to-bloom window and found that cumulative maximum temperature had the lowest coefficient of variation (3.8) and number of days had the highest (8.4). More recently, a comparison of models for studying grapevine phenology under present and future climate scenarios reported that better calibration was found for the early stages that are usually more temperature-driven (Fila et al., 2012). Interestingly, despite marked variation in full-bloom date between our treatments, the number of unfolded leaves counted on shoots at BBCH 65 was the same (12), confirming, as reported by Coombe (1980), that flowering in grapes truly occurs at a given number of formed internodes regardless of shoot length at that specific time.

Temporal sequence of phenological stages as affected by our treatments has two major practical implications. First, that pruning at $\mathrm{BBCH} 12$ (LWP) resulted in a long bud-burst delay (17 days), which seems effective if the goal is to diminish the risk of incurring spring frost; conversely, if the target is also to postpone full ripening, LWP seems unlikely to be effective since the Winkler index of $2291^{\circ} \mathrm{C}$ in our trial environment offers a great deal of compensation throughout the remainder of the season.

Pruning date also notably altered seasonal photosynthetic dynamics and canopy efficiency (Figures 6 and 7). It is well known that upon bud burst the early stages of vine shoot growth are entirely fueled by starch mobilization from the perennial organs (Lebon et al., 2008). Intensity of mobilization progressively fades until the onset of net photosynthesis in the canopy (Zapata et al., 2004). Looking at NCER/canopy trends, we see that the onset of net NCER, i.e., the transition from a sink to source function, took place at the stage of 5-6 unfolded leaves on the shoot across all treatments (Figure 6). This information seems a quite useful update of previous reports indicating that a single leaf becomes a source organ when it reaches between one-third and one-half of final size (Koblet, 1969; Petrie et al., 2000).

Since leaf size varies depending upon node position on the stem, scaling up such information to shoot or canopy leaves is very cumbersome. Generally speaking, our findings for net canopy $\mathrm{CO}_{2}$ thresholds are in agreement with data from Lebon et al. (2004, 2005) and Zapata et al. (2004) indicating that the commencement of net $\mathrm{CO}_{2}$ is synchronous with female meiosis in Pinot Noir, which takes place at $\mathrm{BBCH}-15+2-$ 8 days. Conversely, our results do not confirm that maximum NCER occurs at bloom at canopy scale, as stated in Lebon et al. (2008). Maximum NCER in all our treatments was reached before trimming (i.e., pea size stage) and post-trimming levels were similarly high until the onset of berry color, a window of some 50 days. It is quite clear that, regardless of differences in shoot age, the balance between younger, fully expanded apical leaves and basal ones still retaining good rates of photosynthesis is optimal and, hence, conducive to maximum canopy $\mathrm{CO}_{2}$ assimilation.

Expressing canopy NCER per-unit of leaf area (LA) is a true measure of photosynthetic efficiency of the leaf tissue since confounding effects due to variations in vine size, light exposure, age, degree of healthiness typical of single-leaf sampling are avoided. The trends in Figure 7 show that it took 34 days for NCER/LA in SWP to peak at around $10 \mu \mathrm{mol} \mathrm{m} \mathrm{m}^{-2} \mathrm{~s}^{-1}$. This age strongly supports previous work based on single-leaf assessment showing that maximum leaf $\mathrm{P}_{\mathrm{n}}$ rates are reached at around 3540 days of age, a window slightly in excess of the time a leaf needs to complete expansion (Kriedemann, 1968; Poni et al., 1994). Interestingly, our data confirm that a progressively gradual decline sets in once the peak is reached. This leaf longevity pattern seems rather peculiar to sites affected by high summer temperature. In fact, peak leaf photosynthesis is maintained for longer periods of time when evaluated in cooler climates as was found for Chasselas and Riesling grown in northern European sites (Schultz et al., 1996; Zufferey and Murisier, 2002).

More importantly, both LWP dates considerably reduced the time the foliage needed to reach maximum efficiency (22 days). Anticipating the peak in canopy assimilation per leaf area unit is a totally new and interesting finding and pertains to the mechanisms that the grapevine uses to adapt to unusually late pruning. One possible explanation for this response is that the higher heat summation available during leaf growth for the two late prunings shortened the time leaves needed to reach full size and, hence, maximum photosynthetic potential. As a matter of fact, DD accumulated over bud-break date +30 days were 231, 288, and $362^{\circ} \mathrm{C}$ for SWP, LWP and VLWP, respectively. Noteworthy too is that both LWP and VLWP had NCER/LA rates higher than SWP's at the peak. It is quite well known that leaves developing under higher temperatures can develop a more efficient photosynthetic apparatus primarily because the transpiration stream is more efficient at supplying water, hormones and solutes to the aerial part (Flore and Lakso, 1988). Lastly, when the gradual post-peak decline set in, NCER/LA rates on LWP and VLWP were higher until the end of season so that the late pruning levels could benefit from an extra month of positive net $\mathrm{CO}_{2}$ uptake as compared to SWP, whose last positive NCER/LA value was recorded on DOY 279. Taken together, these three compensation mechanisms, i.e., faster attainment 
and higher seasonal NCER/LA peak and slower late season senescence, all contributed to photosynthetic recovery capacity in late-pruned treatments and, ultimately, explain why even an ample initial delay in growth commencement is difficult to maintain.

The most significant impact that LWP had on vine response regarded yield and its components. Although the impact of the technique on yield will have to be fortified by longer term field studies where the role played by other factors (i.e., the size of the reserve storage pool and the effects that an early source limitation might have on next season bud induction), in our conditions, delaying pruning until BBCH-17 almost offset yield by drastically reducing both cluster number per vine and berry number per cluster. Since it is conceivable that the number of cluster primordia contained in the dormant buds was similar over treatments, attention should focus on those factors inhibiting the conversion of inflorescence primordia to complete inflorescences. According to Carmo Vasconcelos et al. (2009), this process resumes as shoot development begins in the spring during the second season of the bud differentiation cycle and, according to Bernard and Chaliès (1987), continues for 1520 days after bud burst in cvs. Grenache and Carignan. If the $\mathrm{BBCH} 09+20$ days period is considered, it is evident that the compensation point for $\mathrm{CO}_{2}$ exchange was reached at the very end of this window (Figure 8B). Thus the severe source limitation caused by VLWP may have caused pre-developed inflorescence primordia to revert to tendrils. Previous studies have reported that this phenomenon is indeed possible and phosphorous supply (Skinner and Matthews, 1989), early water deficit (Matthews and Anderson, 1989) and application of exogenous gibberellin (Yahyaoui et al., 1998) are among the causal factors involved. Visual monitoring of developing shoots in VLWP rules out the possibility that the phenomenon of filage (verrankung), flower abortion before anthesis with the reversion of the inflorescence to a tendril, took place (Champagnol, 1984).

In LWP, a $26 \%$ reduction in yield per vine was registered, yet due to a different regulation mechanism. In fact, since clusters/shoot, cluster number per vine and berry weight did not differ as compared to SWP, total berry number per cluster only was responsible for the yield constraint (Table 3). Fewer berries per cluster at harvest can derive from multiple factors involving both determinism of initial flower number per cluster and fruitset, which in turn is influenced by a series of factors (May, 2004). Although flower number per cluster was not determined in our study, it is very unlikely that fruit set had been differentially affected by treatment since no adverse weather or severe source limitation was recorded either before or after flowering. Dunn and Martin (2000) in a study on Cabernet Sauvignon vines used delayed pruning to induce bud-burst under different temperature conditions and found that flower number per inflorescence decreased slightly when soil and air temperatures were higher for the days around bud-burst. This did not seem to hold for the SWP vs. LWP comparison of our study since mean air $\mathrm{T}$ calculated over three days around bud-burst resulted in 17.3 and $14.3^{\circ} \mathrm{C}$, respectively.

Rather, vine hormonal status seems to be at work. It is well established that buds made terminal by pruning produce more flowers per cluster than buds in similar node positions but which are not terminal (May, 2004). It is likely that flower formation of the proximal shoots is directly inhibited by auxin imported from the distal shoots which grew earlier (May, 2004). On the other hand, it is also well known that during the second season of the bud differentiation cycle, gibberellins (GAs) cause floral inhibition in Vitis vinifera (Srinivasan and Mullins, 1981). Reproductive growth in the shoot is not totally inhibited by GAs because uncommitted primordia are still made, indicating that the GA signaling acts later by inhibiting the production of floral meristems (Boss and Thomas, 2002). Moreover, GAs are also known to enhance flower drop in grapevine (Domingos et al., 2015; Giacomelli et al., 2015). Overall, endogenous GSs produced during the initial flush of growth in the LWP treatment could be a likely candidate to explain the reduction in berry number per cluster recorded at harvest.

\section{CONCLUSION}

Hypothesis that late or VLWP applied after commencement of spring growth can consistently delay the whole annual growing cycle in the grapevine was partially confirmed. Delay was very pronounced at bud-burst ( +31 days in VLWP vs. C) and significant until fruit-set; hereafter under the warm conditions of our trial site significant compensation occurred. Compensation was especially strong in the LWP treatment due to a shorter time needed to reach maximum NCER/leaf area, highest maximum NCER/leaf area $(+37 \%$ as compared to SWP) and higher NCER/leaf area rates from veraison to end of season. As a result, seasonal cumulated carbon in LWP was $17 \%$ higher than SWP. A negative linear relationship found between total leaf area per vine removed by LWP and yield per vine preliminarily suggests that no more than $10 \%$ of the final leaf area should be removed to prevent excessive yield reduction, thereby making the technique economically unsustainable. Albeit such relationship will have to be strengthened in longer term field studies which, besides including year-to-year variation, can accommodate effects due to different size of storage pools as well as carry-over effects on next season bud induction and differentiation, our LWP response suggests that this treatment may prove to be an excellent substitute for the costly and not entirely reliable cluster thinning practice.

\section{AUTHOR CONTRIBUTIONS}

MG, SP designed and supervised the research; MG, FP, GC, MM performed the research and analyzed the data; MG, SP drafted the manuscript; FP, GC, MM contributed to the whole canopy gas exchange assessment; MG, SP, AP, ST critically revised the manuscript. All authors read and approved the final manuscript.

\section{ACKNOWLEDGMENT}

Authors thank David Verzoni for improving the English style of the text. 


\section{REFERENCES}

Antcliff, A. J., Webster, W. J., and May, P. (1957). Studies on the sultana vine. V. Further studies on the course of bud burst with reference to time of pruning. Aust. J. Agric. Res. 8, 15-23. doi: 10.1071/AR9570015

Bernard, A. C., and Chaliès, C. (1987). "Meiosis in Vitis vinifera cvs grenach and merlot," in Proceedings of the 3rd International Symposium on Grapevine Physiology, eds J. Bouard and R. Pouget (Paris: International Organisation of Vine and Wine), 19-23.

Boss, P. K., and Thomas, M. R. (2002). Association of dwarfism and floral induction with the grape "green revolution" mutation. Nature 416, 847-850. doi: $10.1038 / 416847 \mathrm{a}$

Carmo Vasconcelos, M., Greven, M., Winefield, C. S., Trought, M. C. T., and Raw, V. (2009). The flowering process of Vitis vinifera: a review. Am. J. Enol. Vitic. 60, 412-433.

Champagnol, F. (1984). Éléments de Physiologie de la Vigne et de Viticulture Générale. Montpellier: F. Champagnol.

Chaumont, M., Morot-Gaudry, J. F., and Foyer, C. H. (1994). Seasonal and diurnal changes in photosynthesis and carbon partitioning in Vitis vinifera leaves in vines with and without fruit. J. Exp. Bot. 45, 1235-1243. doi: 10.1093/jxb/45.9.1235

Cola, G., Mariani, L., Salinari, F., Civardi, S., Bernizzoni, F., Gatti, M., et al. (2014). Description and testing of a weather-based model for predicting phenology, canopy development and source-sink balance in Vitis vinifera L. cv. Barbera. Agric. For. Meteorol. 184, 217-236. doi: 10.1016/j.agrformet.2013. 09.008

Coombe, B. G. (1980). Development of the grape berry. I. Effects of time of flowering and competition. Aust. J. Agric. Res. 31, 125-131. doi: 10.1071/AR9800125

Domingos, S., Scafidi, P., Cardoso, V., Leitao, A. E., Di Lorenzo, R., Oliveira, C. M., et al. (2015). Flower abscission in Vitis vinifera L. triggered by gibberellic acid and shade discloses differences in the underlying metabolic pathways. Front. Plant Sci. 6:457. doi: 10.3389/fpls.2015.00457

Dunn, G. M., and Martin, S. R. (2000). Do temperature conditions at budburst affect flower number in Vitis vinifera L. cv. Cabernet Sauvignon? Aust. J. Grape Wine Res. 6, 116-124. doi: 10.1111/j.1755-0238.2000. tb00169.x

Fila, G., Di Lena, B., Gardiman, M., Storchi, P., Tomasi, D., Silvestroni, O., et al. (2012). Calibration and validation of grapevine budburst models using growth-room experiments as data source. Agric. For. Meteorol. 160, 69-79. doi: 10.1016/j.agrformet.2012.03.003

Flore, J. A., and Lakso, A. N. (1988). Environmental and physiological regulation of photosynthesis in fruit crops. Hortic. Rev.11, 111-157.

Friend, A. P., and Trought, M. C. T. (2007). Delayed winter spur-pruning in New Zealand can alter yield components of Merlot grapevines. Aust. J. Grape Wine Res. 13, 157-164. doi: 10.1111/j.1755-0238.2007.tb00246.x

Garcia, R. L., Norman, J. M., and McDermitt, D. K. (1990). Measurement of canopy gas exchange using an open chamber system. Rem. Sens. Rev. 5, 141-162. doi: $10.1080 / 02757259009532126$

Giacomelli, L., Rota-Stabelli, O., Masuero, D., Acheampong, A. K., Moretto, M., Caputi, L., et al. (2015). Gibberellin metabolism in Vitis vinifera L. during bloom and fruit-set: functional characterization and evolution of grapevine gibberellin oxidases. J. Exp. Bot. 64, 4403-4419. doi: 10.1093/jxb/ ert251

Howell, G. S., and Wolpert, J. A. (1978). Nodes per cane, primary bud phenology, and spring freeze damage to Concord grapevines. A preliminary note. Am. J. Enol. Vitic. 29, 229-232.

Iland, P. G. (1988). "Leaf removal effects on fruit composition," in Proceedings of the Second International Cool Climate Viticulture and Oenology Symposium, eds R. E. Smart, R. T. Thorn, S. B. Rodriguez, and J. E. Young (Auckland: New Zealand Society for Viticulture), 137-138.

Keller, M. (2010). Managing grapevines to optimise fruit development in a challenging environment: a climate change primer for viticulturists. Aust. J. Grape Wine Res.16, 56-69. doi: 10.1111/j.1755-0238.2009.00077.x

Koblet, W. (1969). Translocation of photosynthate in vine shoots and influence of leaf area on quantity and quality of the grapes. Wein-Wiss 24, 277-319.
Kriedemann, P. E. (1968). Photosynthesis in vine leaves as a function of light intensity, temperature and leaf age. Vitis 7, 213-220.

Lebon, G., Duchene, E., Brun, O., and Clement, C. (2005). Phenology of flowering and starch accumulation in grape (Vitis vinifera L.) cutting and vines. Ann. Bot. 95, 943-948. doi: 10.1093/aob/mci108

Lebon. G., Duchene, E., Brun, O., Magné, C., and Clément, C. (2004). Flower abscission and inflorescence carbohydrate in sensitive and non sensitive cultivars of grapevine. Sex. Plant Reprod. 17, 71-79. doi: 10.1007/s00497-0040217-9

Lebon, G., Wojnarowiez, G., Holzapfel, B., Fontaine, F., Vaillant-Gaveau, N., and Clement, C. (2008). Sugars and flowering in the grapevine. J. Exp. Bot. 59, 2565-2578. doi: 10.1093/jxb/ern135

Lipka, Z., and Tanner, H. (1974). Une nouvelle méthode de dosage rapide de l'acide tartrique dans les moûts, les vins at autres boissons (selon Rebelein). Rev. Suisse Agric. Vitic. Arboricult. Hortic. 6, 5-10.

Long, S. P., and Hallgren, J. E. (1985). "Measurement of $\mathrm{CO}_{2}$ assimilation by plants in the field and the laboratory," in Techniques in Bioproductivity and Photosynthesis, eds J. Coombs, D. O. Hall, S. P. Long, and J. M. O. Scurlock (Oxford: Pergamon Press), 62-93.

Lorentz, D. H., Eichorn, K. W., Bleiholder, H., Klose, R., Meier, U., and Weber, E. (1995). Phenological growth stages of the grapevine (Vitis vinifera L. ssp. vinifera). Codes and descriptions according to the extended BBCH scale. Aust. J. Grape Wine Res. 1, 100-103. doi: 10.1111/j.1755-0238.1995. tb00085.x

Matthews, M. A., and Anderson, M. M. (1989). Reproductive development in grape (Vitis vinifera L.): responses to seasonal water deficit. Am. J. Enol. Vitic. 40, 52-60.

May, P. (2004). Flowering and Fruitset in Grapevines. Adelaide, SA: Lythrum Press. McIntyre, G. N., Lider, L. A., and Ferrari, N. L. (1982). The chronological classification of grapevine Phenology. Am. J. Enol. Vitic. 33, 80-85.

Palliotti, A., Panara, F., Silvestroni, O., Lanari, V., Sabbatini, P., Howell, G. S., et al. (2013). Influence of mechanical post-veraison leaf removal apical to the cluster zone on delay of fruit ripening in Sangiovese (Vitis vinifera L.) grapevines. Aust. J. Grape Wine Res.19, 369-377.

Palliotti, A., Tombesi, S., Silvestroni, O., Lanari, V., Gatti, M., and Poni, S. (2014). Changes in vineyard establishment and canopy management urged by earlier climate-related grape ripening. a review. Sci. Hortic. 178, 43-54. doi: 10.1016/j.scienta.2014.07.039

Patakas, A., Noitsakis, B., and Stavrakas, D. (1997). Adaptation of leaves of Vitis vinifera L. to seasonal drought as affected by leaf age. Vitis 36, $11-14$.

Petrie, P. R., Trought, M. C. T., and Howell, G. S. (2000). Influence of leaf ageing, leaf area, and crop load on photosynthesis, stomatal conductance and senescence in grapevine (Vitis vinifera L., cv. Pinot noir) leaves. Vitis 39, 31-36.

Poni, S., and Gatti, M., Bernizzoni, F., Civardi, S., Bobeica, N., Magnanini, E. et al., (2013). Late leaf removal aimed at delaying ripening in cv. Sangiovese: physiological assessment and vine performance. Aust. J. Grape Wine Res.19, 378-387. doi: 10.1111/ajgw.12040

Poni, S., and Giachino, E. (2000). Growth, photosynthesis and cropping of potted grapevines (Vitis vinifera L. cv. Cabernet Sauvignon) in relation to shoot trimming. Aust. J. Grape Wine Res. 6, 216-226. doi: 10.1111/j.17550238.2000.tb00182.x

Poni, S., Intrieri, C., and Magnanini, E. (2000). Seasonal growth and gas exchange of conventionally and minimally pruned Chardonnay canopies. Vitis 39, 13-18.

Poni, S., Intrieri, C., and Silvestroni, O. (1994). Interactions of leaf age, fruiting, and exogenous cytokinins in Sangiovese grapevines under non-irrigated conditions. I. Gas exchange. Am. J. Enol. Vitic. 45, 71-78.

Poni, S., Merli, M. C., Magnanini, E., Galbignani, M., Bernizzoni, F., Vercesi, A., et al., (2014). An improved multi-chamber gas exchange system for determining whole canopy water use efficiency in the grapevine. Am. J. Enol. Vitic. 65, 268-276. doi: 10.5344/ajev.2014.13117

Schultz, H. R., Kiefer, W., and Gruppe, W. (1996). Photosynthetic duration, carboxylation efficiency and stomatal limitation of sun and shade leaves of different ages in field-grown grapevine (Vitis vinifera L.). Vitis 35, 169-176. 
Skinner, P. W., and Matthews, M. A. (1989). Reproductive development in grape (Vitis vinifera L.) under phosphorous limited conditions. Sci. Hortic. 38, 49-60. doi: 10.1016/0304-4238(89)90019-8

Sommer, K. J., Clingeleffer, P. R., and Shulman, Y. (1995). Comparative study of vine morphology, growth, and canopy development in cane pruned and minimal-pruned Sultana. Aust. J. Exp. Agric. 35, 265-273. doi: 10.1071/EA9950265

Srinivasan, C., and Mullins, M. G. (1981). Physiology of flowering in the grapevineA review. Am. J. Enol. Vitic.32, 47-63.

Tarara, J. M., and Peña, J. E. P. (2015). Moderate water stress from regulated deficit irrigation decreases transpiration similarly to net carbon exchange in grapevine canopies. J. Am. Soc. Hortic. Sci. 140, 413-426.

Tello, J., and Ibanez, J. (2014). Evaluation of indices for the quantitative and objective estimation of grapevine cluster compactness. Vitis 53, 9-16.

Varela, C., Dry, P. R., Kutyna, D. R., Francis, I. L., Henschke, P. A., Curtin, C. D., et al. (2015). Strategies for reducing alcohol concentration in wine. Aust. J. Grape Wine Res. 21, 670-679. doi: 10.1111/ajgw. 12187

Wermelinger, B., Baumgärtner, J., and Gutierrez, A. P. (1991). A demographic model of assimilation and allocation of carbon and nitrogen in grapevines. Ecol. Mod. 53,1-26. doi: 10.1016/0304-3800(91)90138-Q
Yahyaoui, T., Barbier, M., Bessis, R. (1998). In vitro morphogenesis of grapevine (Vitis vinifera L.) inflorescence primordia, cvs. Pinot noir and Chardonnay. Aust. J. Grape Wine Res. 4, 111-120. doi: 10.1111/j.1755-0238.1998.tb00139.x

Zapata, C., Deléens, E., Chaillou, S., and Magné, C. (2004). Partitioning and mobilization of starch and $\mathrm{N}$ reserves in grapevine (Vitis vinifera L.). J. Plant Phys. 161, 1031-1040. doi: 10.1016/j.jplph.2003.11.009

Zufferey, V., and Murisier, F. (2002). Photosynthèse des feuilles de vigne (cv. Chasselas). II. Adaptation aux conditions environnementales. Rev. Suisse Vitic. Arboric. Hortic. 34, 197-200.

Conflict of Interest Statement: The authors declare that the research was conducted in the absence of any commercial or financial relationships that could be construed as a potential conflict of interest.

Copyright (c) 2016 Gatti, Pirez, Chiari, Tombesi, Palliotti, Merli and Poni. This is an open-access article distributed under the terms of the Creative Commons Attribution License (CC BY). The use, distribution or reproduction in other forums is permitted, provided the original author(s) or licensor are credited and that the original publication in this journal is cited, in accordance with accepted academic practice. No use, distribution or reproduction is permitted which does not comply with these terms. 